\title{
PENGARUH PERCEIVED EASE OF USE PERCEIVED USEFULNESS \\ BRAND IMAGE DAN TRUST TERHADAP PURCHASE INTENTION \\ PRODUK ATTACK JAZ 1 SEMERBAK CINTA DI KECAMATAN KOTAGEDE YOGYAKARTA
}

\author{
Kirwadi \\ Fakultas Ekonomi \\ Universitas Sarjanawiyata Tamansiswa Yogyakarta
}

\begin{abstract}
ABSTRAK
Penelitian ini bertujuan untuk mengetahui pengaruh perceived ease of use, perceived usefulnes, brand image dan trust secara simultan berpengaruh terhadap purchase intention konsumen Attack Jaz 1 Semerbak Cinta Di Kecamatan Kotagede Yogyakarta. Untuk mengetahui pengaruh perceived ease of use, perceived usefulnes, brand image dan trust secara parsial berpengaruh terhadap purchase intention konsumen Attack Jaz 1 Semerbak Cinta Di Kecamatan Kotagede Yogyakarta.

Variabel penelitian ini adalah perceived ease of use, perceived usefulnes, brand image, trust dan purchase intention. Populasi dalam penelitian ini yaitu masyarakat yang memakai produk Attack Jaz 1 Semerbak Cinta di Kecamatan Kotagede Yogyakarta, jumlah sampel penelitian ini 100 responden, hal karena populasi tidak dapat diketahui. Metode pengambilan data menggunakan kuesioner. Teknik analisis yang digunakan adalah regresi linier berganda dengan taraf signifikansi $5 \%$.

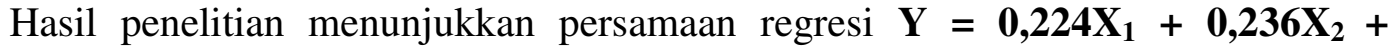

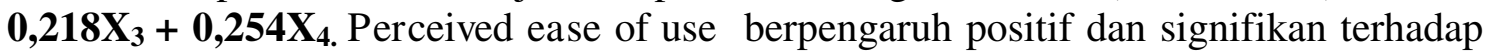
purchase intention, ditunjukkan dengan nilai signifikan $<0,05$. Perceived usefulness berpengaruh positif dan signifikan terhadap purchase intention, ditunjukkan dengan nilai signifikan $<0,05$. Brand image berpengaruh positif dan signifikan terhadap purchase intention, ditunjukkan dengan nilai signifikan $<0,05$. Trust berpengaruh positif dan signifikan terhadap purchase intention, ditunjukkan dengan nilai signifikan < 0,05. Variabel-variabel Preceived ease of use, perceived usefulness, brand image, dan trust berpengaruh secara simultan terhadap purchase intention, ditunjukkan nilai signifikan $\mathrm{F}<0,05$. Purchase intention dipengaruhi Preceived ease of use, perceived usefulness, brand image, dan trust sebesar $54,1 \%$, sedangkan sisanya sebesar $45,9 \%$ dipengaruhi faktor lain.
\end{abstract}

\section{Kata Kunci : Preceived Ease Of Use, Perceived Usefulness, Brand Image, Trust dan Purchase Intention}

\section{PENDAHULUAN}

\section{Latar Belakang Masalah}

Suatu perusahaan tidaklah terlepas dengan adanya persaingan, semakin semakin lama semakin meningkat persaingan di dunia usaha, terutama antara perusahaan yang menghasilkan produk sejenis, dituntut dilakukannya usaha tertentu dalam usaha meningkatkan pangsa pasar perusahaan. Kondisi persaingan yang ketat juga terjadi 
dalam pemasaran produk Attack jaz 1 Semerbak Cinta. Banyaknya merek yang beredar di pasaran mengakibatkan persaingan yang ketat dalam pasar Deterjen. Ketatnya persaingan dapat dilihat dari promosi yang dilakukan oleh masing-masing perusahaan, baik melalui media elektronik maupun media cetak. Selanjutnya perilaku dan selera konsumen yang akan menyeleksi apakah dapat diterima atau ditolak. Bagi konsumen, pembelian bukan hanya merupakan satu tindakan saja, melainkan terdiri dari beberapa tindakan meliputi keputusan tentang perceived ease of use, perceived usefulness, brand image, dan trust terhadap produk. Masing-masing faktor tersebut mendorong konsumen untuk melakukan pembelian. Semakin tinggi keputusan tentang perceived ease of use, perceived usefulness brand image, dan trust terhadap produk, maka semakin tinggi pula minat pembelian konsumen.

Perceived ease of use didefinisikan sebagai sejauh mana seseorang percaya bahwa menggunakan suatu teknologi akan bebas dari usaha. Jika seseorang merasa percaya bahwa sistem informasi mudah digunakan, maka dia akan menggunakannya (Hartono, 2008). Perceived usefulness adalah salah satu penentu utama dari sikap terhadap penggunaan dalam model TAM (Davis et al., 1989, dalam Nurvita Anggraeni dan Lutfi Harris (2013). Tidak hanya itu, menurut Davis 1989 dalam Nurvita Anggreani dan Lutfi Harris 2013, perceived usefulness merupakan penilaian sejauh mana pengguna yakin bahwa teknologi akan meningkatkan kinerja dari suatu kegiatan. Brand image yang positif dihadapan pelanggan, maka mendorong purchase intention konsumen. Brand image yang baik dan positif akan menimbulkan kesan yang baik dalam benak konsumen dalam mengonsumsi suatu. Lin \& Lin (2007) mengatakan bahwa melalui brand image, konsumen akan mudah mengenali sebuah produk, kualitas, mengecilkan resiko pembelian, dan kepuasan terhadap diferensiasi produk tertentu. Trust merupakan pondasi dari bisnis. Membangun trust dalam hubungan jangka panjang dengan pelanggan merupakan suatu faktor yang penting untuk menciptakan minat beli / loyalitas pelanggan. Trust tidak begitu saja dapat diakui oleh pihak lain / mitra bisnis, melainkan harus dibangun mulai dari awal dan dapat dibuktikan

Kotler (2009) menyatakan bahwa pandangan pelanggan terhadap produk merupakan penilaian menyeluruh atas keunggulan suatu produk atau jasa. Pandangan pelanggan yang baik terhadap kualitas jasa suatu produk, maka akan berpengaruh terhadap purchase intention. Seseorang yang mungkin tidak mengenal lebih jelas akan keunggulan sebuah produk dapat memilih produk berkembang secara positif, disebabkan karena produk dapat dipercaya menjadi salah satu faktor yang dapat mempengaruhi purchase intention .

Berdasarkan penjelasan di atas dan dengan melihat pentingnya pelanggan bagi kelangsungan usaha, maka penulis merasa tertarik untuk melakukan penelitian dengan judul : "Pengaruh Perceived ease of use, Perceived usefulnes, Brand Image dan Trust, terhadap Purchase Intention produk Attack Jaz 1 Semerbak Cinta di Kecamatan Kota Gede Yogyakarta".

\section{Rumusan Masalah}

Dari latar belakang masalah, perumusan dalam penelitian ini adalah sebagai berikut:

a. Apakah perceived ease of use, perceived usefulnes, brand image dan trust, secara simultan berpengaruh terhadap purchase intention konsumen Attack Jaz 1 Semerbak Cinta Di Kecamatan Kotagede Yogyakarta?

b. Apakah perceived ease of use, perceived usefulnes, brand image dan trust secara parsial berpengaruh terhadap purchase intention konsumen Attack jaz 1 Semerbak Cinta Di Kecamatan Kotagede Yogyakarta? 


\section{Kajian Teori}

a. Pengaruh perceived ease of use terhadap purchase intention

Persepsi kemudahan penggunaan (perceived ease of use) didefinisikan sebagai sejauh mana seseorang percaya bahwa menggunakan suatu teknologi akan bebas dari usaha. Jika seseorang merasa percaya bahwa suatu produk mudah digunakan, maka dia akan menggunakannya (Hartono, 2008). Persepsi kemudahan penggunaan merupakan penentu utama yang mempengaruhi penerimaan produk tertentu (Davis et al., 1989, dalam Nurvita, 2015).

Nurvita (2015) dalam penelitiannya menunjukkan bahwa persepsi kemudahan penggunaan (perceived ease of use) berpengaruh positif dan signifikan terhadap purchase intention. Nasri dan Charfeddine (2012) menunjukkan bahwa persepsi kemudahan penggunaan (perceived ease of use) memiliki pengaruh yang signifikan terhadap purchase intention. Penelitian Irwan dan Shinta (2014) menyebutkan bahwa persepsi kemudahan penggunaan (perceived ease of use) secara positif dan signifikan berpengaruh terhadap purchase intention. Berdasarkan uraian tersebut, peneliti merumuskan hipotesis alternatif sebagai berikut:

H1 : Semakin meningkat perceived ease of use, maka semakin meningkat purchase intention konsumen.

\section{b. Pengaruh perceived usefulness terhadap purchase intention}

Persepsi kegunaan (perceived usefulness) didefinisikan sebagai sejauh mana seseorang percaya bahwa menggunakan suatu teknologi akan meningkatkan pekerjaannya (Hartono, 2008). Persepsi kegunaan (perceived usefulness) adalah salah satu penentu utama dari sikap konsumen terhadap purchase intention (Davis et al., 1989, dalam Lim dan Ting, 2012). Persepsi kegunaan (perceived usefulness) didefinisikan sebagai sejauh mana pengguna yakin bahwa teknologi akan meningkatkan kinerja dari suatu kegiatan (Davis, 1989, dalam Nurvita, 2015).

Penelitian Nurvita,

menunjukkan bahwa persepsi kegunaan (perceived usefulness) berpengaruh terhadap purchase intention. Renny et al. (2012) menjelaskan bahwa persepsi kegunaan secara positif berpengaruh terhadap purchase intention. Sementara itu, penelitian lain Irwan dan Shinta (2014) juga menjelaskan bahwa persepsi kegunaan secara signifikan dan positif berpengaruh terhadap purchase intention.

Purchase intention merupakan keinginan pelanggan untuk melakukan pembelian. Minat beli merupakan bagian dari perilaku pembelian konsumen di mana kesesuaian antara performa dari produk atau jasa yang ditawarkan perusahaan. Berdasarkan keterangan di atas, maka dapat dihipotesiskan sebagai berikut:

H2 : Semakin meningkat perceived usefulness, maka semakin meningkat purchase intention konsumen.

c. Pengaruh brand image terhadap purchase intention

Brand image merupakan suatu pencitraan sebuah produk dibenak konsumen secara masal. Brand image yang baik dan positif akan menimbulkan kesan yang baik dalam benak konsumen pada saat mengkonsumsi suatu merek (Kotler, 2009). Melalui brand image konsumen akan mudah mengenali sebuah produk, kualitas, mengecilkan resiko pembelian dan kepuasan terhadap diferensiasi produk tertentu. Sehingga dapat meningkatkan minat beli terhadap sebuah barang atau produk dan akan menggunakannya secara terus-menerus (Assael, 2005).

Brand image dapat diartikan sebagai persepsi tentang merek yang 
tercermin oleh asosiasi merek diadakan di memori konsumen. Brand image terdiri dari pengetahuan dan keyakinan konsumen tentang merek.Konsumen yang memiliki persepsi positif terhadap suatu merek berarti merek tersebut memiliki pesan yang kuat dibandingkan dengan pesan merek pesaing Lee, et.al, 2011, dalam Finna dan Sugiono (2015). Sedangkan pengertian brand image menurut Rangkuti (2009) adalah sekumpulan asosiasi merek yang terbentuk di benak konsumen. Konsumen yang terbiasa menggunakan merek tertentu cenderung memiliki konsistensi terhadap merek tersebut.

Peneliti terdahulu yang dilakukan Finna dan Sugiono (2015), menyatakan bahwa brand image berpengaruh positif dan signifikan terhadap purchase intention konsumen. Hal ini didukung peneliti lain Tommy dan Richard (2013) bahwa brand image berpengaruh positif dan signifikan terhadap purchase intention konsumen. Berdasarkan keterangan di atas, maka dapat dihipotesiskan sebagai berikut:

H3 : Semakin meningkat brand image, maka semakin meningkat purchase intention konsumen.

\section{d. Pengaruh trust terhadap purchase} intention

Purchase intention merupakan keinginan pelanggan untuk melakukan pembelian. Minat beli juga merupakan bagian dari perilaku pembelian konsumen di mana kesesuaian antara performa dari produk atau jasa yang ditawarkan perusahaan (Christoper, dkk, 2015). Sedangkan, trust (kepercayaan) didefinisikan sebagai kesediaan (willingness) individu untuk menggantungkan dirinya pada pihak lain yang terlibat dalam pertukaran karena individu mempunyai keyakinan (confidence) kepada pihak lain (Rivita, 2013). Membangun kepercayaan dalam hubungan jangka panjang dengan pelanggan adalah suatu faktor yang penting untuk menciptakan loyalitas pelanggan. Keinginan konsumen untuk membeli suatu produk didasarkan pada kepercayaan yang berkaitan dengan tindakan membeli atau menggunakan produk tersebut. Dari kepercayaan konsumen terhadap sebuah barang atau produk, maka akan memunculkan minat beli di masa yang akan datang.

Peneliti terdahulu yang dilakukan Christoper, dkk, (2015), menyatakan bahwa trust berpengaruh positif dan signifikan terhadap purches intention. Hal ini didukung peneliti lainnya Nurvita (2013) bahwa kepercayaan berpengaruh positif dan signifikan terhadap niat beli ulang konsumen. Berdasarkan keterangan di atas, maka dapat dihipotesiskan sebagai berikut:

H4 : Semakin meningkat trust (kepercayaan) konsumen, maka semakin meningkat purchase intention konsumen.

e. Pengaruh Perceived ease of use, Perceived usefulnes, brand image, dan trust terhadap purchase intention

Seorang pembeli yang memiliki tingkat kepercayan yang tinggi terhadap tenaga penjual dan terhadap produsen yang dimana dia memiliki pengalaman akan lebih mungkin untuk membeli kembali produk tersebut, daripada pelanggan dengan tingkat kepercayaan yang rendah. Menurut burnham et al dalam Christoper, dkk (2015) terdapat empat dimensi yang digunakan dalam menilai suatu purchase intention yaitu melakukan lebih banyak pembelian dengan perusahaan ini dalam waktu dekat, pilihan pertama untuk melakukan pembelian, berniat untuk membeli kembali di perusahaan ini 2 minggu kedepan, dan pelanggan setia di perusahaan ini.

Brand image merupakan asosiasi yang aktif di memori ketika seseorang berpikir tentang merek tertentu Shimp, (2010) dalam Finna dan Sugiono (2015). 
Brand image dapat diartikan sebagai persepsi tentang merek yang tercermin oleh asosiasi merek diadakan di memori konsumen.Brand image terdiri dari pengetahuan dan keyakinan konsumen tentang merek.Konsumen yang memiliki persepsi positif terhadap suatu merek berarti merek tersebut memiliki pesan yang kuat dibandingkan dengan pesan merek pesaing (Nurvita, 2015).

Perceived usefulness merupakan sesuatu yang menyatakan individu percaya bahwa penggunaan suatu teknologi tertentu akan meningkatkan kinerja dari individu. Wibowo (2008) menjelaskan bahwa persepsi kebermanfaatan merupakan suatu ukuran dimana penggunaan suatu teknologi dipercaya akan mendatangkan manfaat bagi orang yang menggunakannya. Persepsi kemudahan didefinsikan sebagai the degree to which a person believe that using a particular system would be free of effort yaitu tingkat kepercayaan seseorang bahwa sistem teknologi tertentu dapat digunakan dengan mudah (tanpa usaha)
(Irwan dan Shinta, 2015). Berdasarkan keterangan di atas, maka dapat dihipotesiskan sebagai berikut:

H5 : Semakin meningkat Perceived ease of use, Perceived usefulnes, brand image dan trust,secara simultan berpengaruh terhadap purchase intention konsumen.

\section{METODE PENELITIAN}

Sifat Peneliian adalah kuantitatif yaitu sifat penelitian yang berwujud angka-angka sebagai dasar bagi setiap penelitian yang bersifat statistic. Variabel penelitian ini adalah perceived ease of use, perceived usefulnes, brand image, trust dan purchase intention. Populasi dalam penelitian ini yaitu masyarakat yang memakai produk Attack Jaz 1 Semerbak Cinta di Kecamatan Kotagede Yogyakarta, jumlah sampel penelitian ini 100 responden, hal karena populasi tidak dapat diketahui. Metode pengambilan data menggunakan kuesioner. Teknik analisis yang digunakan adalah regresi linier berganda dengan taraf signifikansi $5 \%$.

\section{HASIL PENELITIAN DAN PEMBAHASAN}

A. Deskriptif Variabel Penelitian

1. Variabel Preceived Ease Of Use $\left(X_{1}\right)$

Tabel 1

Data Variabel Preceived Ease Of Use $\left(\mathrm{X}_{1}\right)$

\begin{tabular}{|c|c|c|c|}
\hline Kelas & Kategori & Jumlah & Persentase \\
\hline $5-9$ & Sangat Tidak Setuju & 0 & $0 \%$ \\
\hline $10-13$ & Tidak Setuju & 2 & $2 \%$ \\
\hline $14-17$ & Ragu-Ragu & 31 & $31 \%$ \\
\hline $18-21$ & Setuju & 53 & $53 \%$ \\
\hline $22-25$ & Sangat Setuju & 14 & $14 \%$ \\
\hline \multicolumn{2}{|r|}{ Jumlah } & 100 & $100 \%$ \\
\hline
\end{tabular}

Sumber : Data Primer Diolah, (2016)

Dari data di atas diketahui bahwa responden yang menyatakan setuju terhadap preceived ease of use konsumen terhadap produk Attack Jaz 1 Semerbak Cinta ada 53 responden atau $53 \%$, yang menyatakan sangat setuju ada
14 responden atau $14 \%$, yang menyatakan ragu-ragu ada 31 responden atau $31 \%$, yang menyatakan tidak setuju ada 2 responden atau $2 \%$ dan yang menyatakan sangat tidak setuju tidak ada. 


\section{JURNAL MANAJEMEN VOL. 6 N0. 1 JUNI 2016}

\section{Variabel Preceived Usefulness $\left(X_{2}\right)$}

Tabel 2

Data Variabel Preceived Usefulness $\left(\mathbf{X}_{2}\right)$

\begin{tabular}{|c|c|c|c|}
\hline Kelas & Kategori & Jumlah & Prosentase \\
\hline $5-9$ & Sangat Tidak Setuju & 0 & $0 \%$ \\
\hline $10-13$ & Tidak Setuju & 4 & $4 \%$ \\
\hline $14-17$ & Ragu-Ragu & 40 & $40 \%$ \\
\hline $18-21$ & Setuju & 45 & $45 \%$ \\
\hline $22-25$ & Sangat Setuju & 11 & $11 \%$ \\
\hline \multicolumn{2}{|c|}{ Jumlah } & 100 & $100 \%$ \\
\hline
\end{tabular}

Sumber : Data Primer Diolah, (2016)

Dari data di atas diketahui bahwa responden yang menyatakan setuju terhadap preceived usefulness konsumen terhadap produk Attack Jaz 1 Semerbak Cinta ada 45 responden atau $45 \%$, yang menyatakan sangat setuju ada 11 responden atau $11 \%$, yang menyatakan ragu-ragu ada 40 responden atau $40 \%$, yang menyatakan tidak setuju ada 4 responden atau $4 \%$ dan yang menyatakan sangat tidak setuju tidak ada.

\section{Variabel Brand Image $\left(\mathrm{X}_{3}\right)$}

Tabel 3

Data Variabel Brand Image $\left(\mathbf{X}_{3}\right)$

\begin{tabular}{|c|c|c|c|}
\hline Kelas & Kategori & Jumlah & Prosentase \\
\hline $5-9$ & Sangat Tidak Setuju & 0 & $0 \%$ \\
\hline $10-13$ & Tidak Setuju & 3 & $3 \%$ \\
\hline $14-17$ & Ragu-Ragu & 26 & $26 \%$ \\
\hline $18-21$ & Setuju & 50 & $50 \%$ \\
\hline $22-25$ & Sangat Setuju & 21 & $21 \%$ \\
\hline \multicolumn{2}{|r|}{ Jumlah } & 100 & $100 \%$ \\
\hline
\end{tabular}

Sumber : Data Primer Diolah, (2016)

Dari data di atas diketahui bahwa responden yang menyatakan setuju terhadap brand image konsumen terhadap produk Attack Jaz 1 Semerbak Cinta ada 50 responden atau $50 \%$, yang menyatakan sangat setuju ada 21 responden atau $21 \%$, yang menyatakan ragu-ragu ada 26 responden atau $26 \%$, yang menyatakan tidak setuju ada 3 responden atau 3\% dan yang menyatakan sangat tidak setuju tidak ada. 


\section{JURNAL MANAJEMEN VOL. 6 N0. 1 JUNI 2016}

\section{Variabel Trust $\left(X_{4}\right)$}

Tabel 4

Data Variabel Trust $\left(\mathbf{X}_{4}\right)$

\begin{tabular}{|c|c|c|c|}
\hline Kelas & Kategori & Jumlah & Prosentase \\
\hline $5-9$ & Sangat Tidak Setuju & 0 & $0 \%$ \\
\hline $10-13$ & Tidak Setuju & 0 & $0 \%$ \\
\hline $14-17$ & Ragu-Ragu & 27 & $27 \%$ \\
\hline $18-21$ & Setuju & 55 & $55 \%$ \\
\hline $22-25$ & Sangat Setuju & 18 & $18 \%$ \\
\hline \multicolumn{2}{|c|}{ Jumlah } & 100 & $100 \%$ \\
\hline
\end{tabular}

Sumber : Data Primer Diolah, (2016)

Dari data di atas diketahui bahwa responden yang menyatakan setuju terhadap trust/kepercayaan konsumen terhadap produk Attack Jaz 1 Semerbak Cinta ada 55 responden atau 55\%, yang menyatakan sangat setuju ada 18 responden atau $18 \%$, yang menyatakan ragu-ragu ada 27 responden atau $27 \%$ dan yang menyatakan tidak setuju dan sangat tidak setuju tidak ada.

\section{Variabel Purchase Intention $(\mathrm{Y})$}

Tabel 5

Data Variabel Purchase Intention (Y)

\begin{tabular}{|c|c|c|c|}
\hline Kelas & Kategori & Jumlah & Prosentase \\
\hline $5-9$ & Sangat Tidak Setuju & 0 & $0 \%$ \\
\hline $10-13$ & Tidak Setuju & 3 & $3 \%$ \\
\hline $14-17$ & Ragu-Ragu & 37 & $37 \%$ \\
\hline $18-21$ & Setuju & 47 & $47 \%$ \\
\hline $22-25$ & Sangat Setuju & 13 & $13 \%$ \\
\hline \multicolumn{2}{|r|}{ Jumlah } & 100 & $100 \%$ \\
\hline
\end{tabular}

Sumber : Data Primer Diolah, (2016)

Dari data di atas diketahui bahwa responden yang menyatakan setuju terhadap purchase intention konsumen terhadap produk Attack Jaz 1 Semerbak Cinta ada 47 responden atau $47 \%$, yang menyatakan sangat setuju ada 13 responden atau $13 \%$, yang menyatakan ragu-ragu ada 37 responden atau 37\%, yang menyatakan tidak setuju ada 3 responden atau 3\% dan yang menyatakan sangat tidak setuju tidak ada. 


\section{JURNAL MANAJEMEN VOL. 6 N0. 1 JUNI 2016}

B. Analisis Data

1. Uji Asumsi Klasik

a. Uji Normalitas

Tabel 6.

Hasil Uji Normalitas

\begin{tabular}{|ll|r|}
\hline & & $\begin{array}{r}\text { Unstandardize } \\
\text { d Residual }\end{array}$ \\
\hline $\mathrm{N}$ & & 100 \\
Normal Parameters ${ }^{\mathrm{a}, \mathrm{b}}$ & Mean &, 0000000 \\
& Std. Deviation & 1,89596901 \\
Most Extreme & Absolute &, 078 \\
Differences & Positive &, 078 \\
& Negative &,- 047 \\
Kolmogorov-Smirnov Z &, 778 \\
Asymp. Sig. (2-tailed) &, 581 \\
\hline
\end{tabular}

a. Test distribution is Normal.

b. Calculated from data.

Sumber: Data diolah, 2016

Tabel 6. menunjukkan bahwa nilai Kolmogrov-Smirnov Z sebesar 0,778 dan nilai Asymp. Sig. (2-tailed)

sebesar 0,581 yang diperoleh model regresi lebih dari $\alpha(0,05)(0,581>$ $0,05)$, berarti berdistribusi normal.

\section{b. Uji Multikolinearitas}

Tabel 7

Hasil Uji Multikolinieritas

\begin{tabular}{|ll|r|r|}
\hline \multirow{2}{*}{ Model } & \multicolumn{2}{|c|}{ Collinearity Statistics } \\
\cline { 2 - 3 } & \multicolumn{1}{|c|}{ Tolerance } & \multicolumn{1}{c|}{ VIF } \\
\hline 1 & (Constant) &, 510 & 1,963 \\
& Preceived Ease Of & & \\
& Use &, 509 & 1,963 \\
& Perceived Usefulness &, 685 & 1,459 \\
& Brand Image &, 619 & 1,614 \\
& Trust & \\
\hline
\end{tabular}

Sumber: Data diolah, 2016

Dari hasil olah data tersebut, dapat dilihat nilai VIF semua variabel memiliki nilai VIF sekitar 1 atau lebih kecil dari $5(\mathrm{VIF}<5)$, sehingga model regresi tersebut di atas tidak terjadi multikolinieritas sehingga model regresinya dapat digunakan. 


\section{JURNAL MANAJEMEN VOL. 6 NO. 1 JUNI 2016}

\section{c. Uji Heteroskedastisitas}

Adapun grafik scatterplot sebagai berikut:

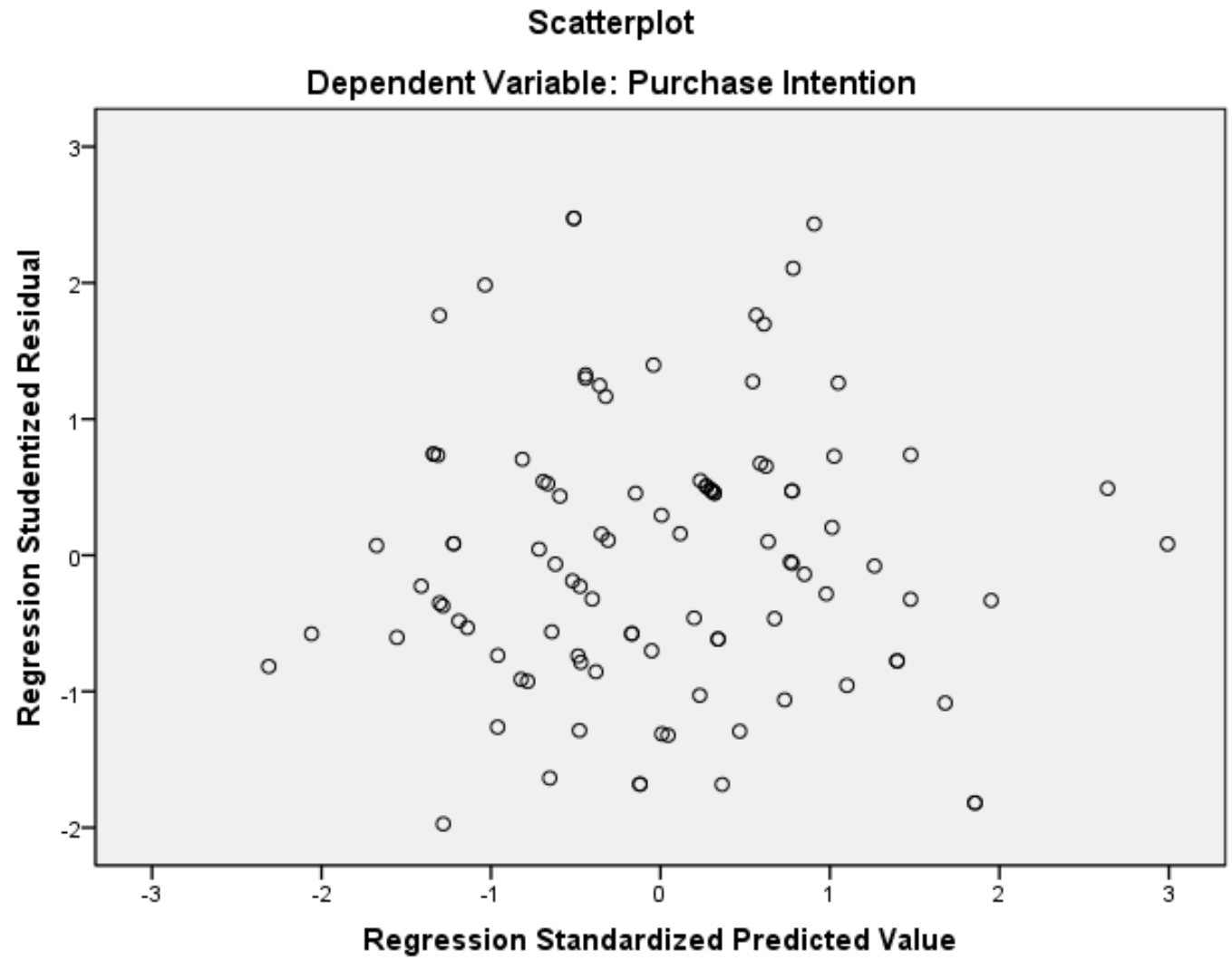

Berdasarkan grafik scaterplot di atas dapat dilihat bahwa penyebaran data menyebar dan tidak membentuk suatu pola, maka dapat disimpulkan data tidak terjadi heterokedatisitas.

\section{Analisis Regresi}

\section{a. Persamaan Regresi Berganda}

\section{Tabel 8}

Hasil Pengujian Regresi Berganda

\begin{tabular}{|ll|r|}
\hline Model & \multicolumn{2}{|c|}{$\begin{array}{c}\text { Standardized } \\
\text { Coefficients }\end{array}$} \\
\cline { 3 - 3 } & & \multicolumn{2}{|c|}{ Beta } \\
\hline $1 \quad$ (Constant) &, 224 \\
& Preceived Ease Of Use &, 236 \\
& Perceived Usefulness &, 218 \\
& Brand Image &, 254 \\
Trust & & \\
\hline
\end{tabular}

Sumber: Data diolah, 2016

$Y=0,224 X_{1}+0,236 X_{2}+0,218 X_{3}+0,254 X_{4}$ 


\section{JURNAL MANAJEMEN VOL. 6 N0. 1 JUNI 2016}

b. Uji t

Tabel 9

Hasil Uji t

\begin{tabular}{|l|r|r|}
\hline Model & \multicolumn{2}{|c|}{} \\
& $\mathrm{t}$ & Sig. \\
\hline (Constant) &,- 259 &, 796 \\
Preceived Ease Of Use & 2,347 &, 021 \\
Perceived Usefulness & 2,476 &, 015 \\
Brand Image & 2,653 &, 009 \\
Trust & 2,940 &, 004 \\
\hline
\end{tabular}

Sumber: Data diolah, 2016

Dari hasil olah data di atas diketahui t-hitung masing - masing variabel adalah :

1) Variabel preceived ease of use t-hitung lebih besar dari t-tabel $(2,347>1,9847)$ dengan probabilitas $(0,021)$ lebih kecil dari taraf signifikan 0,05 , dengan demikian Ho ditolak dan Ha diterima, artinya variabel preceived ease of use mempunyai pengaruh positif dan signifikan terhadap purchase intention.

2) Variabel perceived usefulness thitung lebih besar dari t-tabel $(2,476>1,9847)$ dengan probabilitas $(0,015)$ lebih kecil dari taraf signifikan 0,05 , dengan demikian Ho ditolak dan $\mathrm{Ha}$ diterima, artinya variabel perceived usefulness mempunyai pengaruh positif dan signifikan terhadap purchase intention.

3) Variabel brand image t-hitung lebih besar dari t-tabel $(2,653>$ 1,9847) dengan probabilitas $(0,009)$ lebih kecil dari taraf signifikan $0,05, \quad$ dengan demikian Ho ditolak dan $\mathrm{Ha}$ diterima, artinya variabel brand image mempunyai pengaruh positif dan signifikan terhadap purchase intention.

4) Variabel trust t-hitung lebih besar dari t-tabel $(2,940>$ 1,9847) dengan probabilitas $(0,004)$ lebih kecil dari taraf signifikan $0,05, \quad$ dengan demikian Ho ditolak dan $\mathrm{Ha}$ diterima, artinya variabel trust mempunyai pengaruh positif dan signifikan terhadap purchase intention.

\section{c. Uji F}

Tabel 4.10

Hasil Nilai Uji-F

\begin{tabular}{|ll|c|c|}
\hline Model & F & Sig. \\
\hline 1 & $\begin{array}{l}\text { Regression } \\
\text { Residual } \\
\text { Total }\end{array}$ & 30,223 &, $000^{\mathrm{a}}$ \\
\hline
\end{tabular}

Sumber: Data diolah, 2016 
Dari hasil pengolahan data di atas diketahui bahwa nilai Fhitung adalah 30,223. Dengan nilai signifikan sebesar 0,000 dan nilai F-tabel adalah 3,2257. Dengan demikian dapat disimpulkan bahwa F-hitung $>$ F-tabel dengan tingkat signifikan $0,000<0,05(\mathrm{p}<0,05)$, maka Ho ditolak dan $\mathrm{Ha}$ diterima berarti variabel-variabel preceived ease of use, perceived usefulness, brand image dan trust berpengaruh secara simultan terhadap purchase intention.

\section{d. Koefisien Determinasi}

Tabel 11

Hasil Analisis Uji Koefisien Determinasi $\left(\mathbf{R}^{2}\right)$

\begin{tabular}{|l|r|r|r|r|}
\hline Model & $\mathrm{R}$ & $\begin{array}{c}\mathrm{R} \\
\text { Square }\end{array}$ & $\begin{array}{c}\text { Adjusted R } \\
\text { Square }\end{array}$ & $\begin{array}{c}\text { Std. Error of } \\
\text { the Estimate }\end{array}$ \\
\hline $\mathrm{d} \mathrm{1}$ &, $748^{\mathrm{a}}$ &, 560 &, 541 & 1,93547 \\
$\mathrm{i}$ & & & & \\
$\mathrm{m}$ & & & & \\
$\mathrm{e}$ & & & & \\
$\mathrm{n}$ & & & & \\
$\mathrm{s}$ & & & & \\
$\mathrm{i}$ & & & & \\
$\mathrm{o}$ & & & & \\
$\mathrm{n}$ & & & & \\
0 & & & & \\
\hline
\end{tabular}

Sumber: Data diolah, 2016

Dari perhitungan di atas diperoleh nilai Adjusted $\mathrm{R}^{2}=0,541$ atau $54,1 \%$, hal ini menunjukkan bahwa variasi purchase intention (Y) yang dapat dijelaskan variabel preceived ease of use, perceived usefulness, brand image dan trust sebesar $54,1 \%$, sedangkan sisanya sebesar $45,9 \%$ dipengaruhi faktor lain.

\section{Pembahasan}

Hasil penelitian menunjukkan bahwa Perceived ease of use berpengaruh positif dan signifikan terhadap purchase intention. Adanya pengaruh ini menunjukkan semakin tinggi perceived ease of use, maka akan meningkatkan purchase intention produk Attack Jaz 1 Semerbak Cinta. Sehingga apabila produk Attack Jaz 1 Semerbak Cinta mempunyai kemudahan penggunaan produk atas informasi yang jelas, produk Attack Jas 1, mencuci tidak membutuhkan waktu banyak, merek produk Attack Jas 1 mudah diingat, dan produk Attack Jas 1, memudahkan kemahiran mencuci, maka akan meningkatan purchase intention. Hasil tersebut didukung hasil analisis deskriptif variabel Perceived ease of use, yang menunjukkan bahwa sebagian besar responden menyatakan setuju terhadap preceived ease of use konsumen terhadap produk Attack Jaz 1 Semerbak Cinta ada 53 responden atau $53 \%$.

Hal ini sesuai pendapatan Hartono, (2008), yang menyatakan bahwa jika seseorang merasa percaya bahwa suatu produk mudah digunakan, maka dia akan menggunakannya, persepsi kemudahan penggunaan merupakan penentu utama yang mempengaruhi penerimaan produk tertentu. Hal ini didukung peneliti terdahulu 
Nurvita (2015) persepsi kemudahan penggunaan (perceived ease of use) berpengaruh positif dan signifikan terhadap purchase intention. Peneliti lain Nasri dan Charfeddine (2012) persepsi kemudahan penggunaan (perceived ease of use) memiliki pengaruh yang signifikan terhadap purchase intention. Penelitian Irwan dan Shinta (2014) menyebutkan bahwa persepsi kemudahan penggunaan (perceived ease of use) secara positif dan signifikan berpengaruh terhadap purchase intention.

Perceived usefulness berpengaruh positif dan signifikan terhadap purchase intention. Adanya pengaruh ini menunjukkan semakin tinggi perceived usefulness, maka akan meningkatkan purchase intention produk Attack Jaz 1 Semerbak Cinta. Sehingga apabila produk Attack Jaz 1 Semerbak Cinta dapat mencuci secara cepat, dapat meningkatkan efektifitas mencuci, dapat memudahkan untuk mencuci, dapat menghemat upaya mencuci, dan memberikan kelebihan tidak sekedar mencuci, maka akan meningkatan purchase intention. Hasil tersebut didukung hasil analisis deskriptif variabel Perceived usefulness responden yang menyatakan setuju terhadap preceived usefulness konsumen terhadap produk Attack Jaz 1 Semerbak Cinta ada 45 responden atau $45 \%$.

Hal ini sesuai pendapatan Hartono, (2008), yang menyatakan bahwa persepsi kegunaan (perceived usefulness) adalah salah satu penentu utama dari sikap konsumen terhadap purchase intention. Hal ini didukung peneliti terdahulu Nurvita, (2015) persepsi kegunaan (perceived usefulness) berpengaruh terhadap purchase intention. Renny et al. (2012) persepsi kegunaan secara positif berpengaruh terhadap purchase intention. Sementara itu, penelitian lain Irwan dan Shinta (2014) juga menjelaskan bahwa persepsi kegunaan secara signifikan dan positif berpengaruh terhadap purchase intention.
Brand image berpengaruh positif dan signifikan terhadap purchase intention. Adanya pengaruh ini menunjukkan semakin tinggi brand image, maka akan meningkatkan purchase intention produk Attack Jaz 1 Semerbak Cinta. Sehingga apabila produk Attack Jaz 1 Semerbak Cinta mempunyai citra yang berkualitas, citra Attack Jaz 1 yang mempunyai harga terjangkau, citra Attack Jaz 1 yang memiliki keamanan terhadap kulit di tangan, citra Attack Jaz 1 yang memilki kemasan menarik dan citra Attack Jaz 1 yang memiliki bau wangi, maka akan meningkatan purchase intention. Hasil tersebut didukung hasil analisis deskriptif variabel Brand image responden yang menyatakan setuju terhadap brand image konsumen terhadap produk Attack Jaz 1 Semerbak Cinta ada 50 responden atau $50 \%$.

Hal ini sesuai pendapatan Assael, (2005), yang menyatakan bahwa melalui brand image konsumen akan mudah mengenali sebuah produk, kualitas, mengecilkan resiko pembelian dan kepuasan terhadap diferensiasi produk tertentu. Sehingga dapat meningkatkan minat beli terhadap sebuah barang atau produk dan akan menggunakannya secara terus-menerus Didukung peneliti terdahulu Finna dan Sugiono (2015), menyatakan bahwa brand image berpengaruh positif dan signifikan terhadap purchase intention. Peneliti lain Tommy dan Richard (2013) bahwa brand image berpengaruh positif dan signifikan terhadap purchase intention.

Trust berpengaruh positif dan signifikan terhadap purchase intention. Adanya pengaruh ini menunjukkan semakin tinggi trust, maka akan meningkatkan purchase intention produk Attack Jaz 1 Semerbak Cinta. Sehingga apabila konsumen percaya bahwa produk Attack Jaz 1 Semerbak Cinta mempunyai kualitas yang tidak berubah, memenuhi keinginan konsumen, campuran bahan-bahan sesuai tertera di kemasan, kepercayaan konsumen 
terhadap kualitas Attack Jaz 1 dan kepercayaan konsumen terhadap keandalan produk Attack Jaz 1, maka akan meningkatan purchase intention. Hasil tersebut didukung hasil analisis deskriptif variabel Trust responden yang menyatakan setuju terhadap trust/kepercayaan konsumen terhadap produk Attack Jaz 1 Semerbak Cinta ada 55 responden atau $55 \%$.

Hal ini sesuai pendapatan Finna dan Sugiono (2015), yang menyatakan bahwa membangun kepercayaan dalam hubungan jangka panjang dengan pelanggan adalah suatu faktor yang penting untuk menciptakan loyalitas pelanggan.

Keinginan konsumen untuk membeli suatu produk didasarkan pada kepercayaan yang berkaitan dengan tindakan membeli atau menggunakan produk tersebut. Dari kepercayaan konsumen terhadap sebuah barang atau produk, maka akan memunculkan minat beli di masa yang akan datang. Didukung peneliti terdahulu Christoper, dkk, (2015), menyatakan bahwa trust berpengaruh positif dan signifikan terhadap purches intention. Peneliti lainnya Nurvita (2013) bahwa kepercayaan berpengaruh positif dan signifikan terhadap niat beli ulang konsumen.

Preceived ease of use, perceived usefulness, brand image, dan trust berpengaruh secara simultan terhadap purchase intention. Hal ini menunjukkan apabila Preceived ease of use, perceived usefulness, brand image, dan trust ditingkatkan secara serentak, maka akan meningkatkan purchase intention. Menurut burnham et al dalam Christoper, dkk (2015) terdapat empat dimensi yang digunakan dalam menilai suatu purchase intention yaitu melakukan lebih banyak pembelian dengan perusahaan ini dalam waktu dekat, pilihan pertama untuk melakukan pembelian, berniat untuk membeli kembali di perusahaan ini 2 minggu kedepan, dan pelanggan setia di perusahaan ini. Purchase intention dipengaruhi Preceived ease of use, perceived usefulness, brand image, dan trust sebesar 54,1\%, sedangkan sisanya sebesar 45,9\% dipengaruhi faktor lain.

\section{SIMPULAN}

1. Hasil penelitian diperoleh persamaan regresi sebagai berikut: $\quad \mathbf{Y}=\mathbf{0 , 2 2 4 X _ { 1 }}+\mathbf{0 , 2 3 6 X _ { 2 }}+$ $0,218 X_{3}+0,254 X_{4}$

2. Perceived ease of use berpengaruh positif dan signifikan terhadap purchase intention. Adanya pengaruh ini menunjukkan semakin tinggi perceived ease of use, maka akan meningkatkan purchase intention produk Attack Jaz 1 Semerbak Cinta, hal ini ditunjukkan dengan nilai signifikan $<0,05$.

3. Perceived usefulness berpengaruh positif dan signifikan terhadap purchase intention. Adanya pengaruh ini menunjukkan semakin tinggi perceived usefulness, maka akan meningkatkan purchase intention produk Attack Jaz 1 Semerbak Cinta, hal ini ditunjukkan dengan nilai signifikan $<0,05$.

4. Brand image berpengaruh positif dan signifikan terhadap purchase intention. Adanya pengaruh ini menunjukkan semakin tinggi brand image, maka akan meningkatkan purchase intention produk Attack Jaz 1 Semerbak Cinta, hal ini ditunjukkan dengan nilai signifikan $<0,05$.

5. Trust berpengaruh positif dan signifikan terhadap purchase intention. Adanya pengaruh ini menunjukkan semakin tinggi trust, maka akan meningkatkan purchase intention produk Attack Jaz 1 Semerbak Cinta, hal ini ditunjukkan dengan nilai signifikan $<0,05$.

6. Variabel-variabel Preceived ease of use, perceived usefulness, brand image, dan trust berpengaruh secara simultan terhadap purchase intention, hal ini ditunjukkan nilai signifikan $\mathrm{F}<0,05$.

7. Purchase intention dipengaruhi Preceived ease of use, perceived usefulness, brand image, dan trust sebesar $54,1 \%$, sedangkan sisanya sebesar $45,9 \%$ dipengaruhi faktor lain. 


\section{DAFTAR PUSTAKA}

Assael, H. (2005). Consumer Behavior and Marketing Action 6th edition. New York : International Thomson Publishing.

Davis, Fred D. 1989 "Perceived Usefulness, Perceive Ease of Use, and User Acceptance Information Technology Usefulness", MIS Quarterly, Vol. 13, No. 3, Sep., 1989: pp. 319-340.

Christoper Andretta Handono, Ronald, Amelia, (2015), Analisis Faktor-Faktor yang Mempengaruhi Minat Beli Ulang pada Produk McDonald di Surabaya, Jurnal Gema Aktualita, Vol. 4 No. 1,

Finna Anastasia Wijaya, Sugiono Sugiharto, Pengaruh Celebrity Endorsementterhadap Purchase Intention Denganbrand Image Sebagai Variabel Intervening (Studi Kasus Iklan Produk Perawatan Kecantikan Pond's), Jurnal Manajemen Pemasaran, Vol. 9, No. 1

Ghozali Imam, (2011), Aplikasi Analisis Multivariate Dengan Program SPSS. Semarang : Badan Penerbit Universitas Diponegoro.

Hartono, Jogiyanto. 2008. Sistem Informasi Keperilakuan. Yogyakarta: ANDI

Kotler, Philip. 2009. Manajemen Pemasaran. Jakarta : Erlangga

Lin, Nan Hong \& Lin Bih Shya (2007), The
Efet Of Brand Image and Product Konowlege on Purches Intenstion Modereted by Price Discount, Journal Of Internasional Management Studies.

Nurvita Anggraeni dan Lutfi Harris (2013), Pengaruh Kepercayaan, Persepsi Kegunaan, Dan Persepsi Kemudahan Terhadap Niat Penggunaan Sistem ETicket, Jurnal Ekonomi, Universitas Brawijaya.

Nurvita, Anjarsari, Sarwiji Suwandi, dan Slamet Mulyono. (2015). "Analisis Kesalahan Pemakaian Bahasa Indonesia dalam Karangan Mahasiswa Penutur Bahasa Asing di Universitas Sebelas Maret." BASASTRA Jurnal Penelitian Bahasa, Sastra Indonesia dan Pengajarannya Volume 2 Nomor 1, April 2013, ISSN I2302-6405. Diakses 2 Desember 2015. Sugiyono. (2006). Metode Penelitian Kuantitatif Kualitatif dan RD. Bandung: Alfabeta.

Wibowo, A.2007. Kajian Tentang Perilaku Pengguna Sistem Informasi dengan Pendekatan Technology Acceptance Model (TAM). Jurusan Sistem Informasi, Fakultas Teknologi Informasi. Universitas Budi Luhur.

Tomy Setiawan Ruslim dan Richard Andrew (2013), Pengaruh Brand Image dan Product Knowledge Terhadap Purchese Intention. Universitas Tarumanegara. 